\title{
Genetic improvement of feed conversion ratio via indirect selection against lipid deposition in farmed rainbow trout (Oncorhynchus mykiss Walbaum)
}

\author{
Antti Kause ${ }^{1 *}$, Anders Kiessling ${ }^{2}$, Samuel A. M. Martin ${ }^{3}$, Dominic Houlihan ${ }^{3}$ and Kari Ruohonen ${ }^{4}$ \\ ${ }^{1}$ Biometrical Genetics, Natural Resources Institute Finland, FI-31600 Jokioinen, Finland \\ ${ }^{2}$ Department of Animal Nutrition and Husbandry, Swedish University of Agricultural Sciences, 750 07 Uppsala, Sweden \\ ${ }^{3}$ School of Biological Sciences, University of Aberdeen, Aberdeen AB24 2TZ, UK \\ ${ }^{4}$ EWOS Innovation AS, N-4335 Dirdal, Norway
}

(Submitted 16 March 2016 - Final revision received 9 September 2016 - Accepted 13 September 2016)

\section{Abstract}

In farmed fish, selective breeding for feed conversion ratio (FCR) may be possible via indirectly selecting for easily-measured indicator traits correlated with FCR. We tested the hypothesis that rainbow trout with low lipid\% have genetically better FCR, and that lipid\% may be genetically related to retention efficiency of macronutrients, making lipid\% a useful indicator trait. A quantitative genetic analysis was used to quantify the benefit of replacing feed intake in a selection index with one of three lipid traits: body lipid\%, muscle lipid\% or viscera\% weight of total body weight (reflecting visceral lipid). The index theory calculations showed that simultaneous selection for weight gain and against feed intake (direct selection to improve FCR) increased the expected genetic response in FCR by 1.50-fold compared with the sole selection for growth. Replacing feed intake in the selection index with body lipid\%, muscle lipid\% or viscera\% increased genetic response in FCR by 1.29-, 1.49- and 1.02-fold, respectively, compared with the sole selection for growth. Consequently, indirect selection for weight gain and against muscle lipid\% was almost as effective as direct selection for FCR. Fish with genetically low body and muscle lipid\% were more efficient in turning ingested protein into protein weight gain. Both physiological and genetic mechanisms promote the hypothesis that low-lipid\% fish are more efficient. These results highlight that in breeding programmes of rainbow trout, control of lipid deposition improves not only FCR but also protein-retention efficiency. This improves resource efficiency of aquaculture and reduces nutrient load to the environment.

\section{Key words: Breeding programmes: Feed intake: Index selection: Quantitative genetics}

Feed incurs one of the largest costs in aquaculture production, making the improvement of feed conversion ratio (FCR), the ratio of feed intake:weight gain, of great importance. Selective breeding programmes aim for the genetic improvement of farmed animals. To directly select for FCR, feed intake needs to be recorded, preferably from individual fish. However, fish are typically held in schools and fed together, making the recording of feed intake of individual fish a major challenge ${ }^{(1-4)}$. A potential alternative is to improve FCR by indirect selection for traits that are genetically correlated with FCR. To be successful, such indicator traits need to have a firm biological and physiological relationship with FCR.

Individually recorded feed intake or FCR is currently not selected in any fish breeding programme, and indirect ways of improving FCR may be an effective alternative. Lipid deposition is one potential indicator trait of FCR, because in livestock lean animals are typically more efficient in converting feed to tissue growth compared with fat animals ${ }^{(5,6)}$. In farmed fish, there is some evidence that the control of lipid deposition can be used to genetically improve $\mathrm{FCR}^{(7-9)}$. An additional benefit of controlling lipids is that lipid deposition in different body parts influences fillet quality ${ }^{(10)}$ and slaughter yield ${ }^{(11)}$. In fish, lipid can be recorded non-destructively, making trait recording $\operatorname{appealing}^{(12,13)}$.

Studies on the genetic improvement of FCR in large rainbow trout Oncorbynchus mykiss (Walbaum), marketed at a body weight of $1.5-3 \mathrm{~kg}$, will especially benefit from the assessment of FCR when fish are reaching market size. This is the time when most of the feed is consumed, and hence the time when most of the feeding costs are realised. Moreover, rainbow trout become less efficient with growth. Simultaneously, this is the time when lipid deposition is at its maximum, again reflecting the potential link between lipid deposition and $\mathrm{FCR}^{(14-16)}$.

We quantified the benefit of using lipid deposition as a genetic indicator trait to indirectly select for improved FCR in farmed rainbow trout. Feed intake of individual fish was

Abbreviations: $b$, Regression coefficient; BW, body weight; DFI, daily feed intake; DG, daily weight gain; FCR, feed conversion ratio; $b^{2}$, heritability; HP, high protein; NP, normal protein; RFI, residual feed intake; $r_{\mathrm{G}}$, genetic correlation; $V_{\mathrm{G}}$, genetic variance; $V_{\mathrm{R}}$, residual variance.

* Corresponding author: A. Kause, email antti.kause@luke.fi 
recorded using the X-ray method in which feed pellets are enriched with glass ballotini beads, with the X-ray of a fish revealing the amount of feed consumed ${ }^{(1-4)}$. Specifically, the objectives were as follows: (1) to estimate the genetic correlations of FCR with whole-body lipid\%, muscle lipid\% and viscera $\%$ weight of total body weight (reflecting visceral lipid) ${ }^{(11)}$; (2) to quantify the expected genetic response in FCR when lipid $\%$ recording (indirect selection) is used as the substitute for feed intake recording (direct selection) in a breeding programme; we tested the benefit of replacing feed intake by three alternative lipid traits - body lipid\%, muscle lipid\% and viscera $\%$; and (3) we also tested whether lipid deposition is genetically related to the indicators of retention efficiencies of energy, protein and lipid. The retention efficiencies explicitly quantify the utilisation of macronutrients and energy. A fish can build proteins only from protein (amino acids) in feed, and high-quality proteins are among the most expensive raw materials in an aquafeed formulation, and often of limited supply ${ }^{(17)}$. Hence, effective conversion of protein in feed into tissue is preferred. Lipid in feed is intended to be used especially as an energy source, and excessive levels of lipid deposition in tissues and viscera are not preferred.

\section{Methods}

\section{Experimental fish population}

The experimental fish originated from the Finnish national breeding programme and were housed at the fresh water nucleus station, Tervo Fish Farm, in central Finland. All procedures involving animals were approved by the animal care committee of the Natural Resources Institute Finland. To enhance animal welfare and ameliorate suffering during handling, fish were always anaesthetised using tricaine methanesulfonate (MS-222).

The fish were from 210 families, produced from eighty-nine sires and 109 dams. Each sire was mated to an average of 2.3 dams (range 1-5) and each dam to 1.9 sires (range 1-3). Mating was completed over 3d in April 2001. For the first 8 months after hatching, the families were held separately in 150-litre family tanks, with each family in its own tank. The broodstock fish had been selected for high body weight, late maturity age, silvery skin, spotless skin and body shape for three generations ${ }^{(18)}$

In February 2002, each family was randomly split into two groups to be reared on different experimental diets. The diets were standard, low-protein and high-lipid diets with protein levels of $44.9,44.6$ and $39.5 \%$ and lipid levels of $30.5,30 \cdot 3$ and $33.4 \%$ for pellet sizes of 3,6 and $7 \mathrm{~mm}$, respectively (normal protein (NP) diet). The other diet was an experimental high-protein and low-lipid diet with protein levels of $56 \cdot 4,56 \cdot 3$ and $49 \cdot 4 \%$, and lipid levels of $20 \cdot 7,20 \cdot 6$ and $23.8 \%$ for pellet sizes of 3, 6 and $7 \mathrm{~mm}$, respectively (high-protein (HP) diet). The impact of diets on fish performance has been detailed previously ${ }^{(19,20)}$. The diets were originally used to test the hypothesis that HP diet would reveal individuals that are most efficient in utilising proteins.

The fish were individually tagged to link individuals to the pedigree and to allow for repeated measurements of individuals
(Trovan Ltd). At tagging, fish weight in the two dietary groups was very similar (mean NP 62.4 (SD 19.9) g, 1355 fish and mean HP 62.3 (sD 19.4) g, 1335 fish). During their growth until 29 months of age, some fish were destructively recorded for body composition for a purpose other than the current study $^{(20)}$. Hence, at the end of the experiment, there were 1262 fish remaining.

Each diet treatment was replicated by four $20-\mathrm{m}^{3}$ indoor tanks with fish density of $20 \mathrm{~kg} / \mathrm{m}^{3}$. The families were equally distributed among the tanks. Feeding was automated using computer-controlled pneumatic feeders (Arvo-Tec Inc.), and fish were fed to satiation $4 \mathrm{~h}$ a day. Water temperature during the experiment was natural and exposed to seasonal fluctuations.

\section{Feed utilisation traits recorded}

Body weight, daily feed intake (DFI) and daily weight gain (DG) were recorded three times during growth, in May 2002 (aged 11 months, body weight 142.5 g), October 2002 (aged 16 months, body weight $747 \mathrm{~g}$ ) and September 2003 (aged 27 months, body weight $2113 \mathrm{~g}$ ).

At each time point, a 3-week X-ray session with three repeated measurements of body weight and DFI was performed. Before X-ray studies, all fish from a given tank were fed to satiation $4 \mathrm{~h}$ a day the same way as any other day, but the diet was labelled with radio-opaque ballotini glass beads (Jencons Scientific Ltd). The labelled pellets used at months 11, 16 and 27 consisted of $1,0.5$ and $0.3 \%$ beads, respectively, with a diameter of $400-600 \mu \mathrm{m}$.

To record individual feed consumption with the ballotinienriched feed, fish were X-rayed using a portable X-ray unit (Todd Research 80/20) ${ }^{(1)}$. Each of the eight tanks was measured once weekly (one NP and one HP tank per day). To avoid the potential effects of systematic feeding rhythms, the recording order of NP and HP tanks was reversed on successive days. To initiate a recording session, all fish (X-ray and non-X-ray) were weighed during the 1st week of each session, and DFI was measured from predetermined randomly selected individuals from each family (average of 6.2 fish/family; range 5-7). In the 2nd and 3rd weeks, the procedure was repeated, but only fish $\mathrm{X}$-rayed in the 1 st week were re-weighed and X-rayed again.

\section{Body composition traits recorded}

A total of three lipid traits were recorded at month 29, November 2003, at an average body weight of $2607 \mathrm{~g}$. All fish ( $n$ 1262) from all 210 families were sampled for whole-body lipid\%, muscle lipid\% and viscera\% (100 visceral weight/body weight). Body weight recorded from all fish at month 29 was also used in the analysis $\left(\mathrm{BW}_{\mathrm{M} 29}\right)$. Muscle and chop lipid\% and protein $\%$ of each fish were determined using spectroscopy on the basis of IR transmission ${ }^{(21)}$, and calibrated against analyses by Folch $e a{ }^{(22)}$ and Kjeldahl ${ }^{(23)}$. Muscle was sampled above the lateral line as a $10-\mathrm{g}$ portion of pure epaxial white muscle. Chop was a 3-cm-thick cutlet cut directly from behind the dorsal fin of each fish. Whole-body lipid\% was predicted using predictive equations with chop lipid $\%$, head $\%$, viscera $\%$ and body weight as predictors. The $R^{2}$ of the predictive equation was 
0.62 , and the residual SE was $1.156^{(20)}$. Body protein $\%$ was predicted in the same way, using chop lipid\% and chop protein $\%$ as predictors $\left(R^{2}=0.58 \text {; residual standard error }=0.505\right)^{(20)}$. To minimise the possibility that the relation of feed utilisation with body composition was due to correlative effects with body weight, the statistical models of body lipid\%, muscle lipid $\%$ and viscera\% had body weight at the time of trait recording as a fixed covariate.

The state of maturity (mature, immature) and sex (male, female) were visually recorded at all trait recording times. Males matured at 2, 3 or $3+$ years, females at 3 or $3+$ years, and there were also fish with unknown sex and maturity state.

\section{Definition of feed utilisation traits analysed}

Feed utilisation traits were calculated for two different time periods that are of great importance for producers of large rainbow trout. First, at month 27 (2+ years), four traits were calculated on the basis of the 3-week X-ray trial: average DG and average DFI, based on the records measured across the 3-week period, and $\mathrm{FCR}=\mathrm{DFI} / \mathrm{DG}$. In all statistical models, body weight at the beginning of the 3-week trial was used as a fixed covariate, to correct for the impact of body weight on DG, DFI and FCR. Residual feed intake (RFI), defined as the difference between the observed feed intake and the feed intake predicted from the maintenance costs (metabolic body weight) and growth, was used as a complementary measure of efficiency ${ }^{(24)}$. RFI is phenotypically independent of body size, and is typically considered superior over FCR when animals with different sizes are compared for feed utilisation. For this reason, RFI has been included in the selection indices of many terrestrial livestock species ${ }^{(25,26)}$. RFI was calculated as the residuals from a regression in which metabolic body weight and DG were used as predictors of $\mathrm{DFI}^{(24)}$. Metabolic body weight at the beginning of the 3-week trial was calculated as $\mathrm{BW}^{0.824}$. A low RFI value indicates an efficient fish that feeds less than expected based on its observed growth and maintenance requirements.

Second, five indicators of feed utilisation were calculated across the whole lifetime. An indicator of lifetime FCR was calculated as LifeFCR ${ }_{\text {Indicator }}=$ cumulative feed intake/final body weight at month 29, where cumulative lifetime feed intake ( $\left.\mathrm{LifeFI}_{\text {Indicator }}\right)$ is the sum of all nine DFI records measured at months 11, 16 and

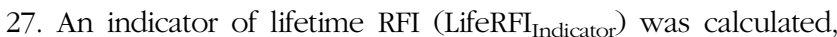
separately for each diet, as the residuals from a regression in which cumulative feed intake was regressed against metabolic body weight at month 16 (measure of average maintenance costs during the feed intake recording) and body weight at month 29 (measure of weight gain). For LifeRFI, the partial regression coefficients for $\mathrm{BW}_{\mathrm{M} 29}$ were 0.0064 and $0.0056(P<0.0001)$ and for metabolic body weight $0.0035(P=0.32)$ and -0.0052 ( $P=0.05$ ) with $R^{2}$ of 33.3 and $14.1 \%$ for the regression models on $\mathrm{NP}$ and HP diets, respectively. At the three separate ages, the partial regression coefficients for DG ranged between 0.2035 and $0.3391(P<0.0001)$ and for metabolic body weight between 0.0017 and 0.0234 (all but one significant) with an average $R^{2}$ of $32.0 \%$ for the regression models (range in $R^{2}=7 \cdot 2-57 \cdot 8 \%$ ). Indicators of lifetime retention efficiencies were calculated for three components, protein (LifeProtRetention Indicator $_{\text {, }}$, lipid and energy as follows: final component weight in a fish (g)/cumulative component intake (g). For instance, LifeProtRetention ${ }_{\text {Indicator }}=$ final protein weight at month $29 /$ cumulative protein intake. In this formula, the numerator trait is recorded from the egg stage onwards, whereas the denominator trait is recorded from average body weight of $142.5 \mathrm{~g}$ onwards during $9 \mathrm{~d}$. Hence, all these traits are called indicators, and their mean value per se has no explicit interpretation. Energy content of a fish was calculated from its protein and lipid weights, assuming an energy concentration of $23.6 \mathrm{~kJ} / \mathrm{g}$ for protein and $39.5 \mathrm{~kJ} / \mathrm{g}$ for lipid $^{(25-27)}$. Feed intake was transformed to intake of the components using the known crude proximate composition of the diets ${ }^{(19)}$.

\section{Statistical analysis}

Phenotypic and genetic variances and correlations were estimated using DMUAI software. The software analyses multivariate mixed models using the restricted maximum likelihood method, and accounts for all relationships between all animals in the pedigree using a relationship matrix ${ }^{(28)}$. The pedigree had 362 ancestors in four generations for the offspring generation used in the experiment. The statistical model for DG, DFI, FCR, body lipid\%, muscle lipid\% and viscera $\%$ to estimate (co)variance components was

Model 1: $y_{i j k l}=\operatorname{anim}_{i}+$ ExpTank $_{j}+$ DietSexMat $_{k}+b_{\mathrm{BW}}$ Diet $_{l}+\epsilon_{i j k l}$,

where anim is the random genetic effect of an animal ( $i=1, \ldots$ number of observations), ExpTank the fixed test tank effect ( $j=1-8$ tanks) DietSexMat the fixed interaction of sex, maturity stage and diet ( $k=1-12$ levels), $b_{\mathrm{BW}}$ the fixed regression coefficient of body weight on $y$, fitted separately for the two diets, Diet $_{l}$ ( $l=1-2$ diets). These body weight-corrected traits are indicated by the $[\mathrm{BW}]$ symbol in the trait abbreviations.

For RFI and all lifetime traits, no additional correction for body weight was needed, and hence the statistical model was

$$
\text { Model 2: } y_{i j k}=\operatorname{anim}_{i}+\operatorname{ExpTank}_{j}+\operatorname{DietSexMat}_{k}+\epsilon_{i j k} .
$$

For all traits, models with the random full-sib family effect (without a link to a pedigree) were also run, in order to quantify the environmental effect common to full sibs. The full-sib family variance $\left(V_{\mathrm{FS}}\right)$ includes common environment effects due to separate rearing of the full-sib families until tagging, but also potential non-additive genetic as well as parts of maternal additive genetic effects. Most of the traits had negligible $V_{\mathrm{FS}}$ (see the Results section), and when including the family effect into the multitrait models the genetic and full-sib family covariances were severely confounded in our data. Hence, for all traits, the correlations were estimated using models excluding the full-family effect.

Heritability was calculated as the genetic variance explained by the animal effect divided by phenotypic variance $\left(V_{\mathrm{P}}\right)$, where $V_{\mathrm{P}}$ is the sum of genetic $\left(V_{\mathrm{G}}\right), V_{\mathrm{FS}}$ and residual variance $\left(V_{\mathrm{R}}\right)$. Full-sib family variance ratio was calculated as $c^{2}=V_{\mathrm{FS}} / V_{\mathrm{P}}$. To assess whether low heritability of a trait results from low genetic variation or from high residual variation, coefficients of genetic $\left(C V_{\mathrm{G}}=100 \sqrt{ } V_{\mathrm{G}} /\right.$ trait mean $)$ and residual variation 
$\left(C V_{\mathrm{R}}=100 \sqrt{ } V_{\mathrm{R}} /\right.$ trait mean) were calculated for traits recorded in grams. $C V$ are not sensible for percentages or ratios ${ }^{(29)}$.

Heritability was considered significantly different from 0 if the $h^{2}$ estimate -0.98 SE did not include 0 (one-tailed hypothesis). Genetic correlation was considered $<$ or $>0$ if the $r_{\mathrm{G}}$ estimate \pm 1.96 sE did not include 0 (two-tailed hypothesis).

\section{Comparison of alternative selection scenarios}

A deterministic simulation was performed with SelAction computer software ${ }^{(30)}$ to quantify the expected genetic response in FCR $\left(\Delta G_{\mathrm{FCR}}\right)$ when using alternative selection indices. The expected genetic response in $\mathrm{FCR}_{[\mathrm{BW}]}$ was calculated, first, when simultaneously selecting for $\mathrm{DG}_{[\mathrm{BW}]}$ and against $\mathrm{DFI}_{[\mathrm{BW}]}$ (direct selection for FCR), and then this scenario was compared with the genetic responses obtained with the index in which feed intake was replaced either by body lipid\% ${ }_{[\mathrm{BW}]}$, muscle lipid\% ${ }_{[\mathrm{BW}]}$ or viscera $\%_{[\mathrm{BW}]}$ (indirect selection). Selection was based on breeding values estimated using individuals' own and the sibs' trait records $^{(30)}$. For each scenario, the relative index weighting of $\mathrm{DFI}_{[\mathrm{BW}]}$ or a lipid trait was increased from 0 (selection for $\mathrm{DG}_{[\mathrm{BW}]}$ only) to 1 (no selection for $\mathrm{DG}_{[\mathrm{BW}]}$ ). $\mathrm{FCR}_{[\mathrm{BW}]}$ was not used in the simulation directly, rather the genetic response in $\mathrm{FCR}_{[\mathrm{BW}]}$ was calculated from the responses of $\mathrm{DFI}_{[\mathrm{BW}]}$ and $\mathrm{DG}_{[\mathrm{BW}]}$.

The phenotypic and genetic parameters estimated using model 1, without the full-sib family effect, were used as input. The simulated population structure was the same for all selection scenarios, to make sure the proportion of selected individuals remained the same across all scenarios. The population size was held small to obtain realistic genetic responses in growth (about $4-10 \% /$ generation $^{(18)}$ ). The population was a full-sib design with 100 selected sires and 100 selected dams, with full-sib family size of four animals, and the proportion of selected animals was 0.50 .

\section{Results}

Feed utilisation at 2+ years of age

Genetic variation for feed utilisation and body composition. For $\mathrm{DG}_{[\mathrm{BW}]}, \mathrm{DFI}_{[\mathrm{BW}]}, \mathrm{FCR}_{[\mathrm{BW}]}$ and composition traits, the full-sib family variance ratio ranged between 0.00 and 0.034 , and therefore for these traits it was safe to focus on the estimates from the model excluding the full-sib family effect (Table 1). $\mathrm{DG}_{[\mathrm{BW}]}, \mathrm{DFI}_{[\mathrm{BW}]}, \mathrm{FCR}_{[\mathrm{BW}]}$ and the composition traits recorded at $2+$ years of age displayed significant heritabilities (Table 1). Heritabilities of feed intake and FCR ranged between $0 \cdot 10$ and $0 \cdot 11$. Heritabilities of lipid traits $\left(b^{2}=0 \cdot 43-0 \cdot 57\right)$ were $4 \cdot 3-5 \cdot 7$ times higher compared with the heritability of feed intake. Both growth and feed intakes showed high coefficients of genetic variation, ranging between $17 \cdot 2$ and $17 \cdot 4$. The coefficient of residual variation was higher for feed intake than for growth, explaining the low heritability observed for feed intake. RFI displayed limited heritability, and when full-family effect was included in the model, the $b^{2}$ estimate was reduced to 0.04 with large sE (Table 1).

Relationship between feed utilisation and growth. DG, corrected for body weight, was phenotypically and genetically favourably correlated with $\mathrm{FCR}_{[\mathrm{BW}]}$ (Table 2). Faster growing fish were more efficient. The correlations between $\mathrm{DG}_{[\mathrm{BW}]}$ and RFI were close to 0 , which was due to the method used to calculate RFI. The correlations of $\mathrm{DG}_{[\mathrm{BW}]}$ with $\mathrm{DFI}_{[\mathrm{BW}]}$ were moderately positive. High RFI was related to high $\mathrm{DFI}_{[\mathrm{BW}]}-$ that is, fish with overly high feed intake were inefficient. A similar, but a weaker, pattern was observed between $\mathrm{FCR}_{[\mathrm{BW}]}$ and $\mathrm{DFI}_{[\mathrm{BW}]}$. RFI and $\mathrm{FCR}_{[\mathrm{BW}]}$ were highly positively correlated, implying that they describe partly the same phenomenon (Table 2).

Relationships between feed utilisation and lipid traits. The low body lipid $\%_{[\mathrm{BW}]}$ and muscle lipid $\%_{[\mathrm{BW}]}$ were both genetically related to low $\mathrm{FCR}_{[\mathrm{BW}]}$ and RFI, confirming the hypothesis that low-lipid\% fish were genetically more efficient (Table 3). This was because $\mathrm{DFI}_{[\mathrm{BW}]}$ was positively, yet non-significantly, genetically related with body lipid\% ${ }_{[\mathrm{BW}]}$ and muscle lipid\%[BW], whereas $\mathrm{DG}_{[\mathrm{BW}]}$ was weakly or even negatively genetically related to these lipid traits.

The $r_{\mathrm{G}}$ of viscera\% ${ }_{[\mathrm{BW}]}$ with growth and feed utilisation were of the opposite sign compared with those of body lipid\%[Bw] and muscle lipid\% $\%_{[\mathrm{BW}]}$, and none of them reached statistical significance (Table 3).

Table 1. Lipid traits and feed utilisation traits recorded at +2 years of age, estimated with an animal model either including or excluding the random full-sibs effect (Sample size $(n)$, trait mean, phenotypic variance $\left(V_{\mathrm{P}}\right)$, heritability and its standard error $\left(h^{2} \pm \mathrm{SE}\right)$, coefficients of genetic $\left(C V_{\mathrm{G}}\right)$ and residual variation $\left(C V_{\mathrm{R}}\right)$ and full-sib effect ratio $\left.\left(c^{2} \pm S E\right)\right)$

\begin{tabular}{|c|c|c|c|c|c|c|c|c|c|c|c|}
\hline \multirow[b]{2}{*}{ Traits* $^{*}$} & \multirow[b]{2}{*}{$n$} & \multirow[b]{2}{*}{ Mean } & \multicolumn{5}{|c|}{ Full-sib effect excluded } & \multicolumn{4}{|c|}{ Full-sib effect included } \\
\hline & & & $V_{\mathrm{P}}^{*}$ & $h^{2}$ & SE & $c V_{\mathrm{G}}$ & $C V_{\mathrm{R}}$ & $h^{2}$ & SE & $c^{2}$ & SE \\
\hline $\mathrm{DG}_{[\mathrm{BW}]}$ & 891 & $16 \cdot 19$ & $27 \cdot 32$ & 0.29 & 0.07 & $17 \cdot 4$ & $27 \cdot 2$ & 0.28 & 0.08 & 0.007 & 0.03 \\
\hline $\mathrm{DFI}_{[\mathrm{BW}]}$ & 815 & $16 \cdot 11$ & 69.58 & 0.11 & 0.06 & $17 \cdot 2$ & $48 \cdot 8$ & 0.07 & 0.06 & 0.023 & 0.03 \\
\hline $\mathrm{FCR}_{[\mathrm{BW}]}$ & 756 & 1.113 & 0.4394 & 0.10 & 0.05 & & & 0.07 & 0.06 & 0.034 & 0.04 \\
\hline RFI & 756 & 0.000 & $64 \cdot 15$ & 0.11 & 0.06 & & & 0.04 & 0.05 & 0.057 & 0.05 \\
\hline Body lipid\%[BW] & 989 & $21 \cdot 27$ & 1.556 & 0.43 & 0.08 & & & 0.43 & 0.09 & 0.000 & 0.03 \\
\hline Muscle lipid\% ${ }_{[B W]}$ & 998 & 7.700 & 4.384 & 0.45 & 0.08 & & & 0.42 & 0.08 & 0.014 & 0.03 \\
\hline Viscera $\%_{[B W]}$ & 1001 & 11.80 & 2.451 & 0.57 & 0.09 & & & 0.57 & 0.12 & 0.000 & 0.03 \\
\hline
\end{tabular}

DG, daily weight gain; [BW], a trait corrected for a constant body weight; DFI, daily feed intake; FCR, feed conversion ratio; RFI, residual feed intake; body lipid\%, body lipid percentage; muscle lipid\%, muscle lipid percentage; viscera\%, viscera percentage of body weight.

* Variance from model 1 or 2 using all the fixed effects that have been removed. 
Expected genetic responses. The selection index calculations showed that selection solely for $\mathrm{DG}_{[\mathrm{BW}]}$ is expected to lead to $+7 \cdot 2 \%$ genetic increase in $\mathrm{DG}_{[\mathrm{BW}]},+2.53 \%$ increase in $\mathrm{DFI}_{[\mathrm{BW}]}$ and consequently to $-4.36 \%$ change in $\mathrm{FCR}_{[\mathrm{BW}]}$ - that is, improvement in FCR (Table 4).

Fig. 1 was used to identify index weightings that maximise the expected genetic response in FCR in alternative selection index scenarios. When having $\mathrm{DG}_{[\mathrm{BW}]}$ and one of the alternative traits in the index, the index weighting that produced the greatest genetic response in FCR was -0.52 for $\operatorname{DFI}_{[\mathrm{BW}]},-0.68$ for body lipid $\%_{[\mathrm{BW}]},-0.70$ for muscle lipid $\%_{[\mathrm{BW}]}$ and -0.10 for viscera\% ${ }_{[\mathrm{BW}]}$ (Table 4). Simultaneous selection for $\mathrm{DG}_{[\mathrm{BW}]}$ and against $\mathrm{DFI}_{[\mathrm{BW}]}$ (direct selection to improve $\mathrm{FCR}$ ) increased genetic response in $\mathrm{FCR}_{[\mathrm{BW}]}$ by 1.50 -fold to $-6 \cdot 54 \%$ compared with the sole selection for $\mathrm{DG}_{[\mathrm{BW}]}$ (Table 4). However, this occurred at the expense of genetic response in $\mathrm{DG}_{[\mathrm{BW}]}$, reducing from $7 \cdot 2$ to $4.83 \%$.

Replacing $\mathrm{DFI}_{[\mathrm{BW}]}$ in the selection index by body lipid\%[BW], muscle lipid\% ${ }_{[\mathrm{BW}]}$ or viscera\% ${ }_{[\mathrm{BW}]}$ increased genetic response in

Table 2. Phenotypic (above diagonal) and genetic correlations (below diagonal) for growth and feed utilisation traits recorded at +2 years of age (Correlations with their standard errors)

\begin{tabular}{|c|c|c|c|c|c|c|c|}
\hline & \multicolumn{2}{|c|}{$\mathrm{DG}_{[\mathrm{BW}]}$} & \multicolumn{2}{|c|}{$\mathrm{DFI}_{[\mathrm{BW}]}$} & \multicolumn{2}{|c|}{$\mathrm{FCR}_{[\mathrm{BW}]}$} & \multirow[b]{2}{*}{ RFI } \\
\hline & Correlation & $\mathrm{SE}$ & Correlation & SE & Correlation & SE & \\
\hline $\mathrm{DG}_{[\mathrm{BW}]}$ & & & 0.29 & & -0.34 & & 0.08 \\
\hline $\mathrm{DFI}_{[\mathrm{BW}]}$ & 0.36 & 0.25 & & & 0.65 & & 0.97 \\
\hline $\mathrm{FCR}_{[\mathrm{BW}]}$ & -0.63 & 0.30 & 0.36 & 0.36 & & & 0.79 \\
\hline RFI & -0.05 & 0.29 & 0.93 & 0.042 & 0.91 & 0.10 & \\
\hline
\end{tabular}

DG, daily weight gain; [BW], a trait corrected for a constant body weight; DFI, daily feed intake; FCR, feed conversion ratio; RFI, residual feed intake.
$\mathrm{FCR}_{[\mathrm{BW}]}$ by 1.29-, 1.49- and 1.02-fold, respectively, compared with the sole selection for $\mathrm{DG}_{[\mathrm{BW}]}$ (Table 4). Hence, using muscle lipid\% ${ }_{[\mathrm{BW}]}$ to indirectly select for FCR was effective, and simultaneously $D_{\mathrm{F}_{[\mathrm{BW}]}}$ improved by $5.93 \%$. These results are in line with the positive $r_{\mathrm{G}}$ of muscle lipid\%[BW] with $\mathrm{FCR}_{[\mathrm{BW}]}$ (and RFI) (Table 3).

\section{Lifetime feed utilisation}

Genetic variation for the indicators of lifetime feed utilisation. For the lifetime traits, $c^{2}$ estimates ranged between 0.037 and 0.065 , and in three out of seven traits the SE was smaller than the $c^{2}$ estimate (Table 5). For these traits, the real heritability is likely to be between the estimates obtained using the two models, one with and one without the full-sib family effect. Similar to +2 years of age, the indicators of lifetime feed intake, FCR, RFI and retention efficiencies (Table 5) displayed lower heritability compared with growth and lipid traits (Table 1). Similar to the traits in +2 years of age, the coefficient of genetic variation was of similar magnitude for $\mathrm{BW}_{\mathrm{M} 29}$ $\left(C V_{\mathrm{G}}=11.6 \% ; C V_{\mathrm{R}}=15.5 \%\right)$ and $\mathrm{LifeFI}_{\text {Indicator }}\left(C V_{\mathrm{G}}=12.7 \%\right.$; $C V_{\mathrm{R}}=40 \cdot 3 \%$ ), but the coefficient of residual variation was higher for $\mathrm{LifeFI}_{\text {Indicator, explaining the low heritabilities of }}$ LifeFI Indicator $_{\text {(Table 5). }}$

Relationship between lifetime feed utilisation and lipid traits. Body weight at month 29 was phenotypically and genetically favourably correlated with LifeFCR Indicator $_{\text {(Table 6). }}$ The correlations of $\mathrm{BW}_{\mathrm{M} 29}$ with lifetime energy, lipid and protein-retention efficiency indicators were also favourably positive but with large standard errors.

The correlations of body lipid\% ${ }_{[\mathrm{BW}]}$, muscle lipid $\%_{[\mathrm{BW}]}$ and viscera\% $\%_{[B W]}$ with LifeFCR $_{\text {Indicator }}$ and LifeRFI Indicator had the

Table 3. Phenotypic $\left(r_{\mathrm{P}}\right)$ and genetic correlations $\left(r_{\mathrm{G}}\right)$ between lipid, growth and feed utilisation traits recorded at +2 years of age $\left(r_{\mathrm{P}}\right.$ and $r_{\mathrm{G}}$ with their standard errors)

\begin{tabular}{|c|c|c|c|c|c|c|c|c|c|}
\hline & \multicolumn{3}{|c|}{ Body lipid\%[BW] } & \multicolumn{3}{|c|}{ Muscle lipid\%[BW] } & \multicolumn{3}{|c|}{ Viscera\%[BW] } \\
\hline & $r_{\mathrm{P}}$ & $r_{\mathrm{G}}$ & SEM & $r_{\mathrm{P}}$ & $r_{\mathrm{G}}$ & SEM & $r_{\mathrm{P}}$ & $r_{\mathrm{G}}$ & SEM \\
\hline $\mathrm{DG}_{[\mathrm{BW}]}$ & 0.14 & -0.07 & 0.18 & 0.07 & -0.26 & 0.17 & 0.13 & 0.29 & 0.16 \\
\hline $\mathrm{DFI}_{[\mathrm{BW}]}$ & 0.09 & 0.37 & 0.26 & 0.06 & 0.41 & 0.24 & 0.09 & 0.09 & 0.23 \\
\hline $\mathrm{FCR}_{[\mathrm{BW}]}$ & 0.01 & 0.58 & 0.28 & 0.04 & 0.68 & 0.24 & -0.02 & -0.39 & 0.23 \\
\hline RFI & 0.07 & 0.48 & 0.27 & 0.05 & 0.57 & 0.24 & 0.06 & -0.07 & 0.24 \\
\hline
\end{tabular}

DG, daily weight gain; [BW], a trait corrected for a constant body weight; DFI, daily feed intake; FCR, feed conversion ratio; RFI, residual feed intake.

Table 4. Expected maximum genetic response $(\Delta G)$ in growth, feed utilisation and lipid traits in response to alternative selection index scenarios ${ }^{\star}$

\begin{tabular}{|c|c|c|c|c|c|c|}
\hline \multirow[b]{2}{*}{ Traits in a selection index ${ }^{*}$} & \multicolumn{6}{|c|}{$\Delta G(\%$ of original trait mean) } \\
\hline & $\mathrm{DG}_{[\mathrm{BW}]}$ & $\mathrm{DFI}_{[\mathrm{BW}]}$ & $\mathrm{FCR}_{[\mathrm{BW}]}$ & Body lipid\% ${ }_{[B W]}$ & Muscle lipid\% ${ }_{[B \mathrm{BW}]}$ & Viscera\% ${ }_{[\mathrm{BW}]}$ \\
\hline $\mathrm{DG}_{[\mathrm{BW}]}$ & $7 \cdot 20$ & 2.53 & $-4 \cdot 36$ & -0.11 & -1.95 & $1 \cdot 19$ \\
\hline $\mathrm{DG}_{[\mathrm{BW}]}-\mathrm{DFI}_{[\mathrm{BW}]}(-0.52)$ & 4.83 & -2.02 & -6.54 & -0.45 & -3.52 & 0.83 \\
\hline $\mathrm{DG}_{[\mathrm{BW}]}$-body lipid\% ${ }_{[\mathrm{BW}]}(-0.68)$ & 6.09 & 0.12 & -5.63 & $-1 \cdot 25$ & 0.25 & 0.41 \\
\hline $\mathrm{DG}_{[\mathrm{BW}]}-$ muscle lipid\% ${ }_{[\mathrm{BW}]}(-0.70)$ & 5.93 & -0.96 & $-6 \cdot 50$ & -1.03 & -7.74 & 0.58 \\
\hline $\mathrm{DG}_{[\mathrm{BW}]}-$ viscera\%$\%_{[\mathrm{BW}]}(-0.10)$ & 7.31 & 2.55 & -4.43 & -0.07 & -1.87 & 1.70 \\
\hline
\end{tabular}

DG, daily weight gain; [BW], a trait corrected for a constant body weight; DFI, daily feed intake; FCR, feed conversion ratio; body lipid\%, body lipid percentage; muscle lipid\%,

muscle lipid percentage; viscera\%, viscera percentage of body weight.

* Relative index weighting given in parentheses. 
same pattern as at +2 years of age, with muscle lipid $\%_{[\mathrm{Bw}]}$ and body lipid\% $\%_{[\mathrm{BW}]}$ having the strongest correlations and viscera $\%_{[\mathrm{BW}]}$ the weakest (Table 6). Decreasing muscle lipid\% ${ }_{[\mathrm{BW}]}$ was genetically related to increased efficiency to use feed (both LifeFCR Indicator $_{\text {and LifeRFI }}$ Indicator).
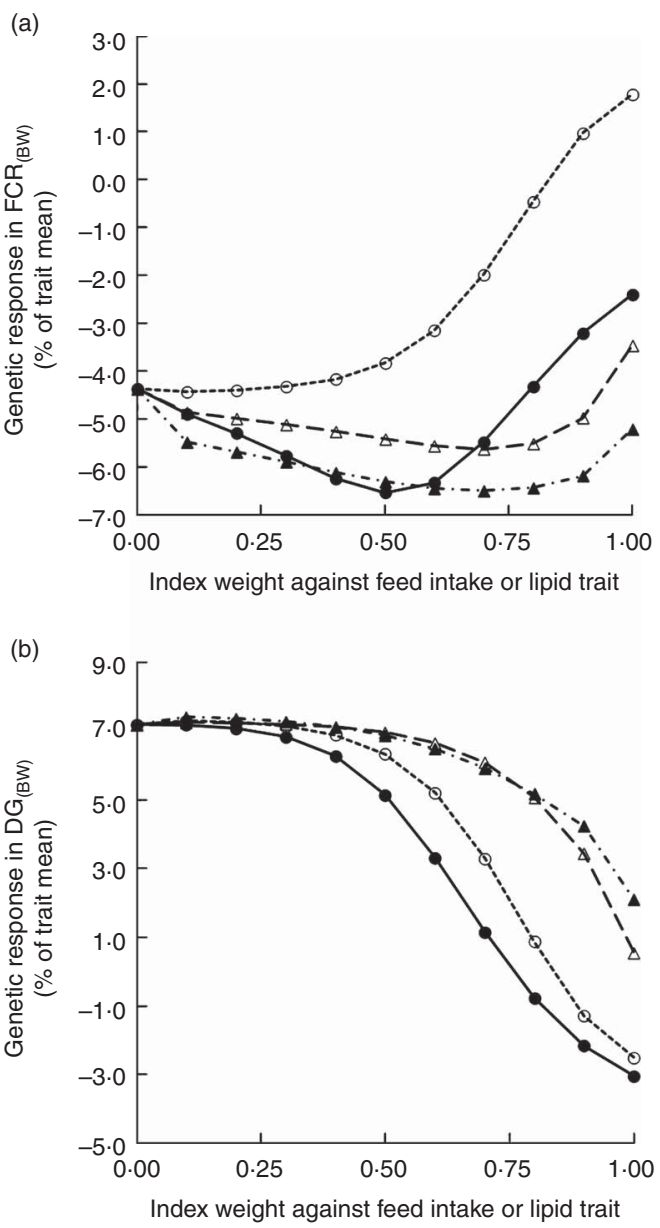

Fig. 1. Expected genetic response in (a) feed conversion ratio $\left(\mathrm{FCR}_{[\mathrm{BW}]}\right)$ and (b) daily weight gain $\left(\mathrm{DG}_{[\mathrm{BW})}\right)$ when selecting simultaneously for $\mathrm{DG}_{[\mathrm{BW}]}$ and against one of the alternative traits: $\mathrm{DFI}_{[\mathrm{BW}]}$ or one of the lipid traits. $-\longrightarrow$, Daily feed intake ${ }_{[\mathrm{BW}]} ; \multimap-$, body lipid\% $\%_{[\mathrm{BW}]} ;-\mathbf{\Delta -}$, muscle lipid\%[BW]; - - -, viscera $\%_{[B W]}$. BW, body weight.
Decreasing muscle lipid\% ${ }_{[\mathrm{BW}]}$ was genetically related to improving lifetime protein-retention efficiency, and the phenotypic correlation $\left(r_{\mathrm{P}}\right)$ of body lipid\% $\%_{[\mathrm{BW}]}$ with LifeProtRetention $_{\text {Indicator }}$ showed the same trend (Table 6). The relationship between body lipid\%[Bw] and muscle lipid\%[Bw] with lifetime lipid and energy retention indicators was weaker than with lifetime protein-retention efficiency.

\section{Discussion \\ Improving feed conversion ratio via control of lipid deposition}

Body composition was genetically related to the efficiency with which fish used feed. At +2 years of age, the lower body lipid $\%$ and muscle lipid\% were genetically related to improved FCR and RFI, confirming the hypothesis that fish with low lipid\% are genetically more efficient. For feed utilisation indicators recorded across the whole lifetime until 29 months of age, the pattern was similar.

The results highlight the benefit of controlling especially muscle lipid on the genetic improvement of FCR in rainbow trout. The index theory calculations showed that direct selection to improve FCR, via simultaneous selection for weight gain and against feed intake, is expected to decrease FCR by 1.50 -fold $\left(\Delta G_{\mathrm{FCR}}=-6.54 \%\right)$ compared with the sole selection for weight gain. There is hence room to improve FCR via methods other than growth selection. When feed intake is replaced in the selection index with muscle lipid\%, such an indirect selection resulted in a maximum genetic response of $-6.50 \%$ in FCR. These results are similar to the ones observed for the use of body lipid\% to indirectly improve FCR in European whitefish Coregonus lavaretus L. ${ }^{(8)}$. In addition, in terrestrial livestock, leaner animals are typically more efficient, and fat traits have positive $r_{\mathrm{G}}$ with $\mathrm{FCR}^{(5,6)}$.

In our selection index calculations, selection responses are determined by (co)variances of the traits. The efficiency of muscle lipid\% as an indirect indicator to improve FCR resulted, first, because of the strong $r_{\mathrm{G}}$ of muscle lipid\% with feed intake and a weaker correlation with weight gain. Selection against muscle lipid\% will hence suppress feed intake more than growth, leading to improved FCR. High levels of feed intake are

Table 5. Lifetime traits estimated with an animal model either including or excluding the random full-sibs effect (Sample size $(n)$, trait mean, phenotypic variance $\left(V_{\mathrm{P}}\right)$, heritability and its standard error $\left(h^{2}\right)$ and full-sib effect ratio $\left.\left(c^{2}\right)\right)$

\begin{tabular}{|c|c|c|c|c|c|c|c|c|c|}
\hline \multirow[b]{2}{*}{ Traits* } & \multirow[b]{2}{*}{$n$} & \multirow[b]{2}{*}{ Mean } & \multicolumn{3}{|c|}{ Full-sib effect excluded } & \multicolumn{4}{|c|}{ Full-sib effect included } \\
\hline & & & $V_{\mathrm{P}}^{*}$ & $h^{2}$ & $\mathrm{SE}$ & $h^{2}$ & SE & $c^{2}$ & SE \\
\hline $\mathrm{BW}_{\mathrm{M} 29}$ & 1262 & 2591 & 252866 & 0.36 & 0.07 & 0.26 & 0.09 & 0.055 & 0.032 \\
\hline LifeFI Indicator & 736 & 21.79 & 84.83 & 0.09 & 0.05 & 0.06 & 0.06 & 0.037 & 0.039 \\
\hline LifeFCR Indicator & 692 & $0 \cdot 845 \mathrm{E}-02$ & $1.46 \mathrm{E}-05$ & 0.13 & 0.07 & 0.07 & 0.07 & 0.048 & 0.047 \\
\hline LifeRFI Indicator & 692 & 0.0000 & 69.439 & 0.14 & 0.08 & 0.06 & 0.06 & 0.065 & 0.062 \\
\hline LifeERetention $_{\text {Indicator }}$ & 545 & $73 \cdot 69$ & 993.61 & 0.10 & 0.07 & 0.05 & 0.07 & 0.046 & 0.053 \\
\hline LifeLipidRetention Indicator & 545 & $124 \cdot 2$ & $3750 \cdot 8$ & 0.13 & 0.08 & 0.07 & 0.06 & 0.049 & 0.053 \\
\hline LifeProtRetention $_{\text {Indicator }}$ & 545 & $48 \cdot 76$ & $416 \cdot 98$ & 0.10 & 0.07 & 0.06 & 0.07 & 0.042 & 0.052 \\
\hline
\end{tabular}

$\mathrm{BW}_{\mathrm{M} 29}$, body weight at month 29; LifeFI Indicator $_{\text {, lifetime feed intake; LifeFCR }}$ Indicator, lifetime feed conversion ratio; LifeRFI Indicator, $_{\text {, lifetime residual feed intake; LifeERetention }}$ Indicator,

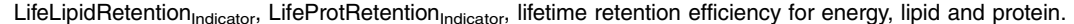

* Variance from model 1 or 2 using all the fixed effects that have been removed. 
Table 6. Lifetime feed utilisation and lipid traits

(Phenotypic $\left(r_{\mathrm{P}}\right)$ and genetic correlations $\left(r_{\mathrm{G}}\right)$ with their standard errors)

\begin{tabular}{|c|c|c|c|c|c|c|c|c|c|c|c|c|}
\hline & \multicolumn{3}{|c|}{$\mathrm{BW}_{\mathrm{M} 29}$} & \multicolumn{3}{|c|}{ Body lipid\% ${ }_{[B W]}$} & \multicolumn{3}{|c|}{ Muscle lipid\% ${ }_{[B W]}$} & \multicolumn{3}{|c|}{ Viscera\% $\%$ BW] } \\
\hline & $r_{\mathrm{P}}$ & $r_{\mathrm{G}}$ & SEM & $r_{\mathrm{P}}$ & $r_{\mathrm{G}}$ & SEM & $r_{\mathrm{P}}$ & $r_{\mathrm{G}}$ & SEM & $r_{\mathrm{P}}$ & $r_{\mathrm{G}}$ & SEM \\
\hline LifeFCR Indicator $_{\text {I }}$ & -0.15 & -0.47 & 0.24 & 0.13 & 0.60 & 0.29 & 0.05 & 0.54 & 0.23 & 0.11 & 0.11 & 0.24 \\
\hline LifeRFI Indicator & 0.05 & -0.04 & 0.27 & 0.09 & 0.29 & 0.28 & 0.05 & 0.64 & 0.25 & 0.08 & -0.23 & 0.23 \\
\hline $\mathrm{BW}_{\mathrm{M} 29}$ & NA & NA & NA & 0.08 & -0.19 & $0 \cdot 17$ & -0.02 & -0.28 & 0.15 & -0.01 & -0.04 & 0.15 \\
\hline LifeFI Indicator & 0.30 & 0.31 & 0.25 & 0.15 & 0.59 & 0.22 & 0.04 & 0.50 & 0.26 & 0.10 & $0 \cdot 16$ & 0.25 \\
\hline LifeERetention $_{\text {Indicator }}$ & 0.02 & 0.24 & 0.28 & -0.04 & -0.08 & 0.29 & 0.02 & -0.46 & 0.30 & -0.06 & 0.20 & 0.26 \\
\hline LifeLipidRetention Indicator & 0.04 & 0.24 & 0.27 & 0.01 & 0.03 & 0.27 & 0.03 & -0.39 & 0.29 & -0.04 & 0.21 & 0.25 \\
\hline LifeProtRetention $_{\text {Indicator }}$ & -0.04 & 0.20 & 0.29 & -0.18 & -0.38 & 0.30 & -0.04 & -0.60 & 0.29 & -0.09 & 0.12 & 0.27 \\
\hline
\end{tabular}

$\mathrm{BW}_{\mathrm{M} 29}$, body weight at month 29; body lipid\%, body lipid percentage; [BW], a trait corrected for a constant body weight; muscle lipid\%, muscle lipid percentage; viscera\%, viscera

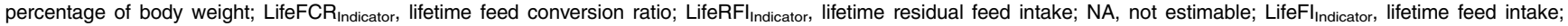
LifeERetention $_{\text {Indicator, LifeLipidRetention }}$ Indicator, LifeProtRetention $_{\text {Indicator, }}$ lifetime retention efficiency for energy, lipid and protein.

likely related to high levels of lipid deposition. Second, muscle lipid\% has higher heritability than feed intake. Lipid traits in general are highly heritable in fish ${ }^{(20)}$. Selection on a highly heritable trait is expected to result in higher genetic responses than selection for a low heritability trait. Hence, indirect selection for a highly heritable trait such as lipid traits can be even more effective than direct selection ${ }^{(31)}$. Feed intake and FCR and retention efficiencies displayed low heritabilities compared with weight gain and BW. DFI is an unusually variable trait in fish $^{(2-4)}$. In addition, recording of long-term feed intake is a major challenge in fish. Using the X-ray method, only snapshots of fish behaviour can be recorded. In our data, this is indicated by the very high residual variation for feed utilisation traits $\left(C V_{\mathrm{R}}>40 \%\right)$. The high residual variance reduces the heritability estimate, even though the genetic variation, measured as $C V_{\mathrm{G}}$, in feed intake is of similar magnitude compared with growth.

In the current study, all lipid traits were recorded destructively, but fillet and muscle lipid can be recorded nondestructively in fish ${ }^{(10,12,13)}$. It is well established that the non-destructive methods can be effectively used to obtain realised genetic response in lipid traits in rainbow trout ${ }^{(7,9)}$, but the non-destructive methods are predictive tools that have measurement errors and are not $100 \%$ accurate ${ }^{(10,12,13)}$. Hence, the use of non-destructive methods to record lipid will reduce the efficiency of indirect selection to improve FCR. Moreover, in line with a general finding ${ }^{(32)}$, in the current study, the $r_{\mathrm{G}}$ were higher than the phenotypic correlations. This may be a real phenomenon, but additionally $r_{\mathrm{G}}$ may become biased when the data set is small.

Naturally, lipid deposition should not be reduced to an extreme because lipid is essential for fish reproduction, lipid is an important source of healthy fatty acids for humans ${ }^{(33)}$, and lipid\% of tissues may have an intermediate optimum for product quality $^{(34)}$. Similar to pigs ${ }^{(35)}$, to define the optimum lipid level would require the combined analysis of economics, biology and novel information on the genetics of the fatty acid profiles. Selection strategies should be further coupled with feeding practices to obtain the desired lipid and fatty acid levels in farmed fish.

It is reliable to use lipid deposition as a genetic indicator trait of FCR in a breeding programme because it has a physiological relationship with FCR. Assume two different fish, one with
$17 \%$ and the other with $25 \%$ body lipid\%. For the time being, we can assume that body protein $\%$ is the same $16 \%$ for both fish, because in general protein $\%$ of tissues is both phenotypically and genetically very invariable in fish ${ }^{(20,36,37)}$. Lipid\% and water\% are inversely correlated in rainbow trout $>50 \mathrm{~g}^{(14,36)}$, and hence only lipid\% and water\% (with no energy value) differ between the two fish. Next, assume that the two fish gain $1 \mathrm{~g}$ of weight and their body composition remains unchanged. The energy content needed for $1 \mathrm{~g}$ of growth for the low- and highlipid\% fish are 10.5 and $13.7 \mathrm{~kJ}$ (assuming the energy concentration of $23.6 \mathrm{~kJ} / \mathrm{g}$ for protein and $39.5 \mathrm{~kJ} / \mathrm{g}$ for lipid), respectively. The cost of depositing different body components does not need to be taken into account because only lipid differs between the fish. Assuming an energy concentration of $20 \mathrm{~kJ} / \mathrm{g}$ for feed and $50 \%$ energy retention efficiency for both fish, the low- and high-lipid\% fish need 1.05 and $1.37 \mathrm{~g}$ of feed to gain $1 \mathrm{~g}$ of weight. These are simply the FCR values of 1.05 for the low-lipid\% fish and 1.37 for the high-lipid\% fish, because we assumed $1 \mathrm{~g}$ of weight gain, proving that decreasing body lipid\%, adjusted for fixed growth, is related to improved efficiency on wet-weight basis. On energy retention basis, the two fish were in fact equally efficient.

As mentioned above, we assumed that body protein $\%$ remained invariable among individuals. It is noteworthy to consider the impact of protein deposition on the efficiency of low-lipid\% fish. In rainbow trout, genetic variation in body and muscle protein $\%$ seems to increase significantly, yet remains low when fish obtain a body weight of $2 \mathrm{~kg}^{(20)}$, a size which is of greatest commercial interest for producers of large rainbow trout. The increased genetic variation in protein\% may be due to the extensive lipid deposition and the large increase in differences for lipid\% between families at this age, forcing protein $\%$, as a side-effect, to vary ${ }^{(20)}$. Moreover, in our data, both body lipid\% $\left(r_{\mathrm{P}}=-0.57 ; r_{\mathrm{G}}=-0.95(\mathrm{SE} \quad 0.05)\right)$ and muscle lipid\% $\left(r_{\mathrm{P}}=-0.33 ; \quad r_{\mathrm{G}}=-0.82(\right.$ se $\left.0 \cdot 12)\right)$ were phenotypically and genetically negatively correlated with the respective protein $\%$ trait. Hence, a low-lipid\% fish was in fact a high-protein\% fish.

One factor making lean animals more efficient is that deposition of protein induces more wet weight gain compared with deposition of lipid ${ }^{(25,26,38)}$. In fish, deposition of $1 \mathrm{~g}$ of lipid is associated with deposition of about $0 \cdot 1 \mathrm{~g}$ of water. Deposition of $1 \mathrm{~g}$ of protein, in turn, is associated with deposition of over 
$3 \mathrm{~g}$ of water. Consequently, the deposition of $1 \mathrm{~g}$ of lipid is expected to lead to a wet weight increase of $1.1 \mathrm{~g}$ (partial regression coefficient $b_{\text {lipid }}=1 \cdot 1$ ), whereas the deposition of $1 \mathrm{~g}$ of protein is expected to lead to $4-5 \mathrm{~g}$ of wet weight gain $\left(b_{\text {protein }}=4-5\right)^{(25,26,38,39)}$. The partial regression coefficients can be calculated from our data by regressing simultaneously both lipid and protein body weight (on x-axis) against final wet weight (y-axis). In line with the literature, our data showed $b_{\text {lipid }}=1.45$ and $b_{\text {protein }}=4.24$ for the NP diet ( $n 416$ fish) and $b_{\text {lipid }}=1.55$ and $b_{\text {protein }}=4.12$ for the HP diet ( $n 482$ fish). Consequently, protein weight gain generally results in significantly more wet weight gain compared with lipid gain. This phenomenon facilitates that lean fish, with high protein weight gain, are more efficient, when efficiency is measured on wet-weight basis.

However, depositing $1 \mathrm{~g}$ of protein $(59.9 \mathrm{~kJ} / \mathrm{g}$ of protein) is energetically more expensive than depositing $1 \mathrm{~g}$ of lipid ( 55.3 and $43.5 \mathrm{~kJ} / \mathrm{g}$ from non-lipid and lipid origins). These approximate values were calculated assuming energy concentrations of protein and lipid of 23.6 and $39.5 \mathrm{~kJ} / \mathrm{g}$ and net energy costs of $2.54,1.4$ and $1.1 \mathrm{~kJ}$ per $\mathrm{kJ}$ for protein and lipid retention from non-lipid or lipid origins, respectively ${ }^{(40)}$. The values that Emmans ${ }^{(40)}$ provided are calculated for terrestrial animals, but costs of protein deposition appear to be similar across terrestrial and aquatic animals, whereas costs of lipid deposition vary more ${ }^{(40)}$. The higher cost of protein deposition does not overule the efficiency of protein deposition because the higher energy cost is small compared with the 4-5-fold effect on the increased wet weight gain.

Maximising genetic improvement in FCR reduces considerably the genetic response in weight gain, which may not be desirable (Fig. 1). Hence, the target of selection should be to obtain an economically optimised balance between genetic changes in weight gain, feed intake and FCR, to make economically more efficient fish. This can be obtained by calculating economic values of the traits - for example, by using bio-economic models ${ }^{(34,41)}$.

Muscle lipid\% but not viscera\% was related to feed utilisation. Visceral lipid is a major portion of viscera weight, and viscera $\%$ can be regarded as a lipid trait ${ }^{(11)}$. Lipid deposits at different body locations are genetically different traits, and hence they are expected to have different correlations with other traits $^{(20,42-44)}$. Viscera\% is easy to record in a breeding programme when sibs of breeding candidates are slaughtered, and selection against viscera\% can be used to genetically improve fillet $\%$ and reduce slaughter waste, as is practiced in the Finnish breeding programme for rainbow trout ${ }^{(11)}$. Unfortunately, our data indicate no additional impact on improved feed utilisation.

\section{Getting around wet weight-based traits: the retention efficiencies}

The wet weight-based traits such as FCR, weight gain and body weight are traits important to fish farmers. Farmers who sell their fish to processors or directly to retailers are paid based on the wet weight growth of fish, typically gutted weight. However, pelleted feed has low water concentration (2-10\%) and fish ingest large amounts of water to obtain high body water concentration (70-80\%). To directly assess the efficiency with which macronutrients and energy of the feed are used, the analysis of indicators of protein, lipid and energy retention efficiency was performed.

The results show that restricting excessive lipid deposition in a rainbow trout breeding programme improves proteinretention efficiency. This is favourable for aquaculture, because even a small improvement in protein-retention efficiency has a large economic impact on the industry. Highquality protein raw materials are among the most expensive components in an aquafeed formulation, and are often of limited supply ${ }^{(17)}$. Moreover, protein is the source of $\mathrm{N}$, and the more $\mathrm{N}$ from feed is deposited into fish, the smaller the nutrient load to the environment will be per produced $\mathrm{kg}$ of fish.

In contrast to protein-retention efficiency, the effective genetic improvement of lipid retention may be of less importance. In feed formulation, lipid is especially meant to be used as a major energy source for fish, sparing protein to be used for tissue growth ${ }^{(45)}$. Hence, improving lipid retention efficiency too much would make fish to allocate more of the ingested lipid to deposited lipid, which may not be optimal. Yet, the improvement in retention of EPA and DHA $n-3$ fatty acids would be of importance as these are the main healthy components for humans. Moreover, fish need lipid deposits for basic life functions, and a suitable level of lipid is required in farmed fish for fulfilling standards of eating quality. Accordingly, the ultimate goal for both animal breeding and feed development would be a fish that optimally partitions different macronutrients between tissue growth and energy requirements.

The observation that fish with genetically low body lipid\% and muscle lipid\% were more efficient in turning ingested protein into protein weight gain can be partly explained by the negative relationship between lipid $\%$ and protein $\%$. The 'low-lipid\%-high-protein\%' fish have high protein-retention efficiency. Indeed, in our data, body protein\% ${ }_{[\mathrm{BW}]}$ was phenotypically and genetically related to improved indicator of lifetime protein-retention efficiency $\left(r_{\mathrm{P}}=0 \cdot 15 ; r_{\mathrm{G}}=0.81\right.$ (SE 0.32)). Our findings are similar to the genetic responses observed when selecting for low and high muscle lipid\%, corrected for body weight, lines in rainbow trout. The line with low muscle lipid\% has improved feed efficiency and protein efficiency ${ }^{(7,9,46,47)}$.

Detailed studies on protein synthesis have revealed some of the mechanisms behind the highly efficient fish. Protein synthesis is costly, requiring about $11-42 \%$ of energy expenditure $^{(48)}$, and hence fish that grow more efficiently achieve this through adopting the low-protein turnover strategy ${ }^{(49)}$. A reduction in protein turnover, brought about by lower degradation of synthesised proteins, leads to increased protein and wet weight growth efficiency. In this way, some individuals achieve faster and more efficient protein accretion when consuming the same amount of food as individuals with slower and less-efficient growth ${ }^{(50)}$.

It is worth noting that our observations and that of previous studies $^{(7,9,46,47)}$ on among-individual variation differ from the results of diet comparisons. In contrast to our results, it is commonly found in diet comparisons that high-lipid diet enhancing lipid deposition improves protein-retention efficiency. 
This protein-sparing effect occurs because the excess lipid in the diet fulfils the energy requirements of fish, allowing them to allocate ingested protein for growth, and less to maintenance ${ }^{(45)}$. Naturally, effects of diets on a pair of fish traits do not need to be of the same direction as the phenotypic traits, and especially the $r_{\mathrm{G}}$ between the same traits. For instance, the use of plant-based ingredients in feed can increase feed intake and decrease body lipid\% compared with a fully fish-based diet, but simultaneously, within each diet, fish with high feed intake can have high lipid $\%{ }^{(8)}$.

\section{Implications}

In many fish species, lipid deposition is controlled in fish breeding programmes because of its impact on reduced slaughter waste, increased fillet $\%$ and quality ${ }^{(11)}$. Our study and other studies $^{(7-9,46,47)}$ have contributed to the growing evidence that the control of excess lipid deposition by selective breeding programmes would bring an additional benefit of improving not just FCR but also protein-retention efficiency in fish.

\section{Acknowledgements}

The staff at Tervo station, Ossi Ritola and Tuija Paananen, are highly acknowledged for fish management.

The research leading to these results has received funding from the European Union's Seventh Framework Programme (KBBE.2013.1.2-10) under grant agreement no. 613611 FISHBOOST. Moreover, the original data collection was supported by the European Union, Project PROGRESS Q5RS-2001-00994.

A. Kause, A. Ki., S. A. M. M., D. H. and K. R. designed the study and wrote the paper; A. Kause analysed the data and had primary responsibility for the final content. All the authors read and approved the manuscript.

The authors declare that there are no conflicts of interest.

\section{References}

1. Talbot C \& Higgins PJ (1983) A radiographic method for feeding studies on fish using metallic iron powder as marker. J Fish Biol 23, 211-220.

2. Jobling M, Baardvik BM \& Jørgensen EH (1989) Investigation of food-growth relationships of Arctic charr, Salvelinus alpinus L., using radiography. Aquaculture 81, 367-372.

3. Houlihan D, Boujard T \& Jobling M (editors) (2001) Food Intake in Fish. Oxford: Blackwell.

4. Kause A, Tobin D, Dobly A, et al. (2006) Recording strategies and selection potential of feed intake measured using the X-ray method in rainbow trout. Genet Sel Evol 38, 389-410.

5. Pym RAE (1990) Nutritional genetics. In Poultry Breeding and Genetics, pp. 847-876 [RD Crawford, editor]. Oxford: Elsevier.

6. Archer JA, Richardson EC, Herd RM, et al. (1999) Potential for selection to improve efficiency of feed use in beef cattle: a review. Aust J Agric Res 50, 147-161.

7. Quillet E, Le Guillou S, Aubin J, et al. (2007) Response of a lean muscle and a fat muscle rainbow trout (Oncorbynchus mykiss) line on growth, nutrient utilization, body composition and carcass traits when fed two different diets. Aquaculture 269, 220-231.

8. Quinton C, Kause A, Ruohonen K, et al. (2007) Genetic relationships of body composition and feed utilization traits in
European whitefish (Coregonus lavaretus L.) and implications for selective breeding in fishmeal- and soybean meal-based diet environments. J Anim Sci 85, 3198-3208.

9. Kamalam BS, Medale F, Kaushik S, et al. (2012) Regulation of metabolism by dietary carbohydrates in two lines of rainbow trout divergently selected for muscle fat content. J Exp Biol 215, 2567-2578.

10. Kause A, Quinton CD, Airaksinen S, et al. (2011) Quality and production trait genetics of farmed European whitefish, Coregonus lavaretus. J Anim Sci 89, 959-971.

11. Kause A, Paananen T, Ritola O, et al. (2007) Direct and indirect selection of visceral lipid weight, fillet weight and fillet percent in a rainbow trout breeding programme. J Anim Sci 85, 3218-3227.

12. Brown MR, Kube PD, Taylor RS, et al. (2014) Rapid compositional analysis of Atlantic salmon (Salmo salar) using visible-near infrared reflectance spectroscopy. Aquacult Res 45, 798-811.

13. He HJ, Wu D \& Sun DW (2015) Nondestructive spectroscopic and imaging techniques for quality evaluation and assessment of fish and fish products. Crit Rev Food Sci Nutr 55, 864-886.

14. Kiessling A, Åsgård T, Storebakken T, et al. (1991) Changes in the structure and function of the epaxial muscle of rainbow trout (Oncorbyncus mykiss) in relation to ration and age. III: chemical composition. Aquaculture 93, 373-387.

15. Einen O \& Roem AJ (1997) Dietary protein/energy ratios for Atlantic salmon in relation to fish size: growth, feed utilization and slaughter quality. Aquac Nutr 3, 115-126.

16. Azevedo PA, Leeson S, Cho CY, et al. (2004) Growth, nitrogen and energy utilization of juveniles from four salmonid species: diet, species and size effects. Aquaculture 234, 393-414.

17. Tacon AGJ, Hasan MR \& Metian M (2011) Demand and Supply of Feed Ingredients for Farmed Fish and Crustaceans: Trends and Prospects. FAO Fisheries and Aquaculture Technical Paper no. 564. Rome: FAO.

18. Kause A, Ritola O, Paananen T, et al. (2005) Genetic trends in growth, sexual maturity and skeletal deformations, and rate of inbreeding in a breeding programme for rainbow trout. Aquaculture 247, 177-187.

19. Kause A, Tobin D, Houlihan DF, et al. (2006) Feed efficiency of rainbow trout can be improved through selection: different genetic potential on alternative diets. J Anim Sci 84, 807-817.

20. Tobin D, Kause A, Mäntysaari EA, et al. (2006) Fat or lean? The quantitative genetic basis for selection strategies of muscle and body composition traits in breeding programmes of rainbow trout (Oncorbynchus mykiss). Aquaculture 261, 510-521.

21. Elvingsson P \& Sjauna LO (1992) Determination of fat, protein and dry matter content of fish by mid-infrared transmission spectroscopy. Aquacult Fish Manage 23, 453-460.

22. Folch J, Lees M \& Sloane-Stanley G (1957) A simple method for the isolation and purification of total lipides from animal tissues. J Biol Chem 226, 497-504.

23. Kjeldahl J (1883) Neue methode zur bestimmung des stickstoffs in organischen körpern (New method for determination of nitrogen content in organic tissues). Z Anal Chem 22, 366-382.

24. Koch RM, Swiger LA, Chambers D, et al. (1963) Efficiency of feed use in beef cattle. J Anim Sci 22, 486-494.

25. Herd RM (2009) Residual feed intake. In Resource Allocation Theory Applied to Farm Animal Production, pp. 89-109 [WM Rauw, editor]. Wallingford: CAB International.

26. Jobling M (1994) Fish Bioenergetics. London: Chapman \& Hall.

27. Kiessling A, Higgs DA, Eales JG, et al. (1994) Influence of sustained exercise at two ration levels on growth and thyroid function of all-female chinook salmon (Oncorbynchus tshawytscha Walbaum) in sea water. Can J Fish Aquat Sci 51, 1975-1984. 
28. Madsen P \& Jensen J (2013) DMU version 6. http://dmu. agrsci.dk/DMU/Doc/Current/dmuv6_guide.5.2.pdf (accessed January 2016).

29. Houle D (1992) Comparing evolvability and variability of quantitative traits. Genetics 130, 195-204.

30. Rutten MJM, Bijma P, Woolliams JA, et al. (2002) SelAction: software to predict selection response and rate of inbreeding in livestock breeding programs. J Hered 93, 456-458.

31. Falconer DS (1952) The problem of environment and selection. Am Nat 86, 293-298.

32. Cheverud JM (1988) A comparison of genetic and phenotypic correlations. Evolution 42, 958-968.

33. Tocher DR (2003) Metabolism and functions of lipids and fatty acids in teleost fish. Rev Fisheries Sci 11, 107-184.

34. Kankainen M, Setälä J, Kause A, et al. (2016) Economic values of supply chain productivity and quality traits calculated for a farmed European whitefish breeding program. Aquacult Econ Manage 20, 131-164.

35. Sellier P (1998) Genetics of meat and carcass traits. In The Genetics of the Pig, pp. 463-510 [MF Rothschild and A Ruvinsky, editors]. Wallingford: CAB International.

36. Shearer KD (1994) Factors affecting the proximate composition of cultured fishes with emphasis on salmonids. Aquaculture 119, 63-88.

37. Kause A, Quinton CD, Ruohonen K, et al. (2009) Genetic potential for the regulation of variability in body lipid and protein content of European whitefish Coregonus lavaretus. Br J Nutr 101, 1444-1451.

38. Cho CY \& Kaushik SJ (1990) Nutritional energetics in fish: energy and protein utilization in rainbow trout (Salmo gairdneri). World Rev Nutr Diet 61, 132-172.

39. Dumas A, de Lange CFM, France J, et al. (2007) Quantitative description of body composition and rates of nutrient deposition in rainbow trout (Oncorbynchus mykiss). Aquaculture $\mathbf{2 7 3}$ 165-181.

40. Emmans GC (1994) Effective energy: a concept of energy utilization applied across species. Br J Nutr 71, 801-821.
41. Kankainen M, Setälä J, Berrill IK, et al. (2012) How to measure the economic impacts of changes in growth, feed efficiency and survival in aquaculture. Aquacult Econ Manage 16, 341-364.

42. Gjerde B \& Schaeffer LR (1989) Body traits in rainbow trout: II. Estimates of heritabilities and of phenotypic and genetic correlations. Aquaculture 80, 25-44.

43. Kause A, Ritola O, Paananen T, et al. (2002) Coupling body weight and its composition: a quantitative genetic analysis in rainbow trout. Aquaculture 211, 65-70.

44. Kause A, Stien LH, Rungruangsak-Torrissen $\mathrm{K}$, et al. (2008) Image analysis as a tool to facilitate selective breeding of quality traits in rainbow trout. Livestock Sci 114, 315-324.

45. Grayton RD \& Beamish FWH (1977) Effects of feeding frequency on food intake, growth and body composition of rainbow trout (Salmo gairdneri). Aquaculture 11, 159-172.

46. Kolditz CI, Borthaire M, Richard N, et al. (2008) Liver and muscle metabolic changes induced by dietary energy content and genetic selection in rainbow trout (Oncorbynchus mykiss). Am J Physiol Regul Integr Comp Physiol 294, 1154-1164.

47. Skiba-Cassy S, Lansard M, Panserat S, et al. (2009) Rainbow trout genetically selected for greater muscle fat content display increased activation of liver TOR signalling and lipogenic gene expression. Am J Physiol Regul Integr Comp Physiol 297, $1421-1429$

48. Houlihan DF, Hall SJ, Gray C, et al. (1988) Growth rates and protein turnover in Atlantic cod, Gadus morbua. Can J Fish Aquat Sci 45, 951-964.

49. Carter CG, Houlihan DF \& Owen SF (1998) Protein synthesis, nitrogen excretion and long-term growth of juvenile Pleuronectes flesus. J Fish Biol 53, 272-284.

50. McCarthy ID, Houlihan DF \& Carter CG (1994) Individual variation in protein turnover and growth efficiency in rainbow trout, Oncorbynchus mykiss. Proc R Soc Lond B Biol Sci 257, 141-147. 